\title{
Predictors of success and failure in pulmonary rehabilitation
}

\author{
R. Garrod*, J. Marshall*, E. Barley" and P.W. Jones ${ }^{\#}$
}

ABSTRACT: The purpose of the present study was to identify prognostic features of chronic obstructive pulmonary disease (COPD) associated with success or failure in pulmonary rehabilitation. Patients were stratified according to the Medical Research Council (MRC) dyspnoea score.

A total of 74 stable COPD patients (mean \pm SD age $68 \pm 10$ yrs), 21 MRC dyspnoea score grade 1/2, 29 grade $3 / 4$ and 24 grade 5 , with a mean forced expiratory volume in one second of $1.1 \pm 0.6 \mathrm{~L}$, attended for rehabilitation. Assessments consisted of the following: quadriceps torque, 6-minute walking distance (6MWD), Brief Assessment Depression Cards and St George's Respiratory Questionnaire (SGRQ). Predictors of drop-out and of response (a change in SGRQ of four points or 6MWD of $\mathbf{5 4} \mathrm{m}$ ) were tested using binary logistic regression.

In total, 51 patients completed the study. Of these, $39(77 \%)$ showed a clinically significant benefit in either 6MWD or SGRQ. Baseline variables were poor predictors of response in each case. Significant differences were seen between MRC dyspnoea score groups for change in 6MWD and SGRQ Score. Only grade 1/2 and 3/4 patients improved. Depression was a risk factor for subject drop-out compared with nondepressed patients.

Baseline state is a poor predictor of response to rehabilitation, although Medical Research Council dyspnoea score grade 5 patients showed smaller magnitudes of improvement than patients with less severe Medical Research Council dyspnoea score grades. Risk of drop-out is significantly greater in depressed compared with nondepressed patients.

KEYWORDS: Chronic obstructive pulmonary disease, nondepressed, prediction, pulmonary rehabilitation, response

$\mathbf{W}$ hilst there is a significant body of research supporting the efficacy of pulmonary rehabilitation in patients with chronic obstructive pulmonary disease (COPD), there is still surprisingly little known concerning the predictors of success and failure in pulmonary rehabilitation. Recent evaluation of clinical services suggests that, whilst the mean response to pulmonary rehabilitation is good, a number of patients are achieving little or no clinical benefit from the service [1]. Similarly, a retrospective analysis from the UK showed that although most patients benefited, almost 30\% of those who went through the programme were nonresponders in terms of health status or exercise tolerance [2]. However, there were no clear differences between responder and nonresponder groups based on routine variables of lung function or exercise ability. A number of hypotheses have been put forward to explain response behaviour, ranging from airflow obstruction $[3,4]$ to baseline exercise tolerance [5]. These studies have been inconclusive, generally due to poor design, regression to the mean effects or small sample size.

In a more recent study, it was found that those patients with impaired muscle performance and less ventilatory limitation to exercise were more likely to improve with exercise training [1]. However, these variables explained only a small amount of the response to pulmonary rehabilitation. The study by TroOsters et al. [1] was performed in patients with moderate-to-severe airflow limitation, these being the patients who suffer greater symptoms but are still able to access the service. Patients with milder symptoms or made housebound by severe dyspnoea were not included. Housebound COPD patients remain a neglected group, with access limitations making outpatient rehabilitation difficult, whilst home-training programmes are no more effective than an education programme alone [6]. In the present study, patients were stratified using the Medical Research Council (MRC) dyspnoea score, and grade 5 patients, those "unable to leave the house due to breathlessness", were seen
AFFILIATIONS

*School of Physiotherapy, Faculty of Health and Social Care Sciences, and ${ }^{\text {\#Cardiac and Vascular Services, St }}$ George's Hospital, University of

London, London, UK.

CORRESPONDENCE

R. Garrod

School of Physiotherapy

Faculty of Health and Social Care

Sciences

St George's

University of London and Kingston University

Cranmer Terrace

Tooting

London SW17 ORE

UK

Fax: 442087252248

E-mail: rgarrod@hscs.sgul.ac.uk

Received:

November 082005

Accepted after revision:

January 312006 
at home. Lower grades visited the hospital as outpatients. Therefore, a methodological limitation of the present study concerns the fact that the rehabilitation programmes under investigation differed, as did the severity of the patients [6]. At the other end of the spectrum, patients with mild disease may be considered "too well" to benefit from rehabilitation. British Thoracic Society (BTS) guidelines [7] and National Institute for Clinical Effectiveness guidelines recommend inclusion of patients using MRC dyspnoea score grades 3-5 [8]. However, patients with mild disability (MRC 1-2) have not previously been entered into studies, implying that guidelines may be hampered by a lack of evidence in this group.

The purpose of the current study was to identify prognostic features of COPD associated with short- and long-term success or failure in pulmonary rehabilitation. To ensure that a wide range of severity was studied, patients from all grades of the MRC dyspnoea score were recruited.

\section{METHODS}

\section{Patients}

Patients were recruited from primary and secondary care services. A total of 111 patients with a known diagnosis of COPD [9] were sent invitation letters. Of those who responded, 16 declined to participate and 87 made initial assessment appointments. In total, 74 of these patients attended initial assessment. All provided written informed consent. All patients had limited exercise tolerance due to dyspnoea. Transport to the hospital by taxi was provided where required. Exclusion criteria consisted of unstable angina, recent exacerbation or change of medication, intermittent claudication or other mobility limiting conditions. Full ethical consent was obtained from Merton Sutton and Wandsworth Health Authority Local Research Ethics Committee (London, UK).

Patients were stratified according to baseline breathlessness using the MRC dyspnoea scale [10]. For the purposes of analysis, the five MRC dyspnoea scale grades were recategorised into three levels of severity of breathlessness: mild, moderate and severe. Mild patients were those who described themselves as "troubled by breathlessness on strenuous exertion" or "short of breath when hurrying" (i.e. MRC dyspnoea scale grades 1 and 2). Moderate patients described themselves as having to "walk slower than most people (of my own age) on the level" or needing to "stop for breath after walking about one hundred yards on the level" (i.e. MRC dyspnoea scale grades 3 and 4). Severe patients described themselves as "too breathless to leave the house or breathless after undressing" (i.e. MRC dyspnoea scale grade 5).

\section{Primary outcomes}

Two objective and two patient-reported measures of health were selected as primary outcomes, as follows:

\section{Sub-maximal exercise tolerance}

The 6-minute walking distance (6MWD) was performed along a $30 \mathrm{~m}$ corridor, according to American Thoracic Society instructions [11], and the best of two repeatable tests were taken (repeatability was defined as a difference between walks of $<50 \mathrm{~m}$ ). Results of the 6MWD were recorded as actual values and as per cent predicted of normative data (\% pred) [12].

\section{Quadriceps strength}

This was assessed using a Cybex Norm $\mathbb{A}$ Testing and Rehabilitation System, in accordance with the manufacturer's instructions (Phoenix Healthcare, Shrewsbury, UK). The equipment was set to test knee extension isokinetically, in seated mode, starting from full knee flexion. A speed of $60^{\circ}$ per second was selected. Maximum torque was recorded as the best of three attempts from the dominant side (Nms) and as:

$$
\text { Nms/subject bodyweight }(\mathrm{kg}) \times 100
$$

Health status

This was assessed using the St George's Respiratory Questionnaire (SGRQ) [13]. This 50-item, disease-specific, self-complete questionnaire has been validated to measure health impairment in respiratory patients. Scores range from 100 (worst possible health status) to 0 (best possible health status).

\section{Depression}

The Brief Assessment Schedule Depression Cards were used to assess depression [14]. A score of seven or above indicates a case of depression.

\section{Secondary outcomes}

\section{Grip strength}

The patient's dominant hand was tested using a Baseline ${ }^{\mathrm{TM}}$ Hydraulic Hand Dynamometer (Derbyshire, UK). The best of three attempts was recorded (in $\mathrm{kg}$ ).

\section{Maximal inspiratory and expiratory pressure}

These were measured using Jeager Masterscreen Body ${ }^{\mathrm{TM}}$ equipment. The best of three attempts for both maximal inspiratory and expiratory pressure was recorded and expressed as \% pred.

\section{Breathlessness during daily activities}

This was assessed using the London Chest Activity of Daily Living Scale, a 15-item questionnaire designed to measure dyspnoea during routine daily activities in patients with COPD. Higher scores represent maximal disability $[15,16]$.

\section{Self-efficacy}

This was assessed using the COPD Self-Efficacy Scale, a 34item questionnaire, which has been shown to be both reliable and internally consistent [17]. Higher scores represent greater self-efficacy.

\section{Baseline assessments}

Patient details (age, sex, body mass index, smoking history), lung function (forced expiratory volume in one second (FEV1) and forced vital capacity) and maximal oxygen consumption were assessed prior to rehabilitation using a Sensormatics (IM) Vmax 29c Cardiopulmonary Exercise Testing Instrument in accordance with the manufacturer's instructions. Calibration was performed within $1 \mathrm{~h}$ prior to assessment. Patients performed an incremental maximal treadmill test according to the protocol of NAUGHTON et al. [18]. A short practice attempt was made $30 \mathrm{~min}$ before the actual test and patients were encouraged to exercise to maximal capacity. Ventilatory reserve was calculated using the maximum voluntary ventilation $(\mathrm{FEV} 1 \times 40)$ ratio to maximal ventilation. Percutaneous 
oxygen saturation and heart rate were monitored and recorded at 1-min intervals throughout the test. Breath-by-breath analysis was recorded every $30 \mathrm{~s}$.

\section{The rehabilitation programme}

The rehabilitation programme was delivered over 7 weeks, patients attended twice weekly as outpatients. Provision was made for additional attendance due to missed sessions. Each session comprised of $1 \mathrm{~h}$ of exercise followed by an education session.

The exercise programme has been previously described [2] and was delivered in accordance with BTS standards [7]. Patients were asked to undertake a simple home exercise programme for $\sim 20 \mathrm{~min} \cdot \mathrm{day}^{-1}, 5$ day $\cdot \mathrm{week}^{-1}$, in addition to attending an educational class.

\section{Effect of pulmonary rehabilitation}

Drop-outs versus completers

Patients were considered to be a "completer" if they had attended at least 10 out of the 14 possible sessions.

\section{Responders versus nonresponders}

For two of the present author's outcome measures, clinically significant improvement has been previously determined. For the $6 \mathrm{MWD}$ a change of $\geqslant 54 \mathrm{~m}$ is considered clinically significant [19], and for SGRQ total score, the clinically important difference is represented by a change of $\geqslant 4$ points
[20]. Since improvement in either of these variables is beneficial, and because changes in different outcomes following rehabilitation have been found to be unrelated, the current authors used a composite measure of response. Accordingly, patients considered to be responders were those who showed clinically significant improvement in either 6MWD or SGRQ score.

To help determine the response to treatment, the changes in scores were also calculated for the primary outcomes by subtracting the baseline value from that at post-rehabilitation.

\section{Analyses}

All data were normally distributed, except Borg score pre6MWD. Data for this variable were log transformed to achieve normality. Comparisons were made between responders and nonresponders, and between drop-outs and completers, using unpaired t-tests. Predictors of drop-out and of response to pulmonary rehabilitation were tested using binary logistic regression. Predictors of change in the primary outcomes were tested using forward stepwise linear regression.

Differences between patients with mild, moderate and severe breathlessness at baseline were tested using one-way ANOVA. Differences in changes in health for these groups were tested using ANCOVA to control for baseline health; follow-up score was the dependent variable, breathlessness was the independent variable and baseline score was the covariate. Contrasts

TABLE 1 Baseline characteristics by disease severity

\begin{tabular}{|c|c|c|c|}
\hline \multirow[t]{2}{*}{ Subjects $n$} & \multicolumn{3}{|c|}{ Disease severity } \\
\hline & $\begin{array}{c}\text { Mild } \\
(\text { MRC grade 1/2) }\end{array}$ & $\begin{array}{c}\text { Moderate } \\
\text { (MRC grade 2/3) }\end{array}$ & $\begin{array}{c}\text { Severe } \\
\text { (MRC grade 5) }^{+}\end{array}$ \\
\hline
\end{tabular}

\begin{tabular}{|c|c|c|c|c|c|}
\hline Age yrs & 74 & $63.6 \pm 11.4$ & $67.9 \pm 9.6$ & $73.2 \pm 7.9$ & 0.005 \\
\hline Smoking pack-yrs ${ }^{\S}$ & 73 & $38.1 \pm 28.0$ & $48.8 \pm 39.3$ & $51.7 \pm 30.9$ & NS \\
\hline Quadriceps torque $(\mathrm{Nms} / \mathbf{k g} \times 100)$ & 74 & $123.5 \pm 35.5$ & $123.0 \pm 55.0$ & $83.9 \pm 36.8$ & 0.003 \\
\hline SGRQ score s $^{\S}$ & 74 & $38.0 \pm 14.8$ & $61.2 \pm 12.9$ & $65.5 \pm 14.2$ & $<0.0001$ \\
\hline FEV1 \% pred & 73 & $65.7 \pm 20.0$ & $43.0 \pm 24.4$ & $38.1 \pm 16.9$ & $<0.0001$ \\
\hline MEP \% pred & 66 & $98.2 \pm 44.0$ & $87.9 \pm 32.1$ & $77.4 \pm 34.6$ & NS \\
\hline$V^{\prime} \mathrm{O}_{2}, \max \mathrm{kg} \cdot \mathrm{L}^{-1} \cdot \mathrm{min}^{-1}$ & 71 & $16.2 \pm 7.0$ & $10.9 \pm 6.0$ & $7.1 \pm 1.9$ & $<0.0001$ \\
\hline Grip \% pred & 74 & $109.9 \pm 17.6$ & $102.6 \pm 24.0$ & $99.3 \pm 25.1$ & NS \\
\hline Borg score pre-6MWD $\mathrm{m}^{\S}$ & 72 & $0.2 \pm 0.3$ & $0.7 \pm 0.7$ & $1.0 \pm 1.1$ & 0.009 \\
\hline Borg score post-6MWD $\mathrm{m}^{\S}$ & 72 & $3.1 \pm 1.4$ & $3.7 \pm 0.9$ & $4.5 \pm 1.5$ & 0.002 \\
\hline
\end{tabular}

Differences were tested using ANOVA. Data are presented as mean (SD). A high score indicates better health, unless otherwise indicated ( ${ }^{\S}$ : low score $=$ better health). MRC: Medical Research Council; BMI: body mass index; 6MWD: 6-minute walk distance; SGRQ: St George's Respiratory Questionnaire; FEV1: forced expiratory volume in one second; \% pred: per cent predicted; FVC: forced vital capacity; MIP: maximal inspiratory pressure; MEP: maximal expiratory pressure; $V^{\prime} \mathrm{O}_{2}$,max: maximal oxygen consumption; $\mathrm{Sa}, \mathrm{O}_{2}$ : arterial oxygen saturation; COPDSE: Chronic Obstructive Pulmonary Disease Self-Efficacy Scale; LCADL: London Chest Activity of Daily Living Scale. \#: $n=21 ; \bullet: n=29 ;{ }^{+}: n=24 ;$ NS: nonsignificant. 
were performed to test which groups differed. Where multiple tests were performed, significance was accepted at $p=0.01$. Data are presented as mean \pm SD.

\section{RESULTS}

\section{Patient details}

A total of 74 patients entered the study (mean age $68 \pm 10$ yrs; 41 male). Of these, 10 were current smokers, 62 were exsmokers and two had never smoked. The mean number of smoking pack-yrs was $46.6 \pm 33.8$ yrs. Nine patients fitted the criteria for MRC dyspnoea score grade 1, 12 for grade 2, 10 for grade 3, 19 for grade 4 and 24 for grade 5. Mean attendance rate was $71 \%$. Post-rehabilitation data was available for 51 patients who completed at least 10 of the 14 sessions.

\section{Baseline differences according to MRC dyspnoea score grade}

Baseline characteristics for patients of each level of severity of breathlessness are reported in table 1. For all the primary outcomes, except depression, patients with a higher MRC dyspnoea score grade had the worst scores (table $1 ; \mathrm{p}<0.003$ ). Severity of breathlessness was not associated with smoking, sex or depression $(p>0.05)$.

\section{Change in primary outcomes}

A total of $51(69 \%)$ patients completed the course of pulmonary rehabilitation. Figure 1 shows the changes in these outcomes for all patients following pulmonary rehabilitation. Improvement was significant for the 6MWD and SGRQ $(p<0.0001)$. Changes in scores for the primary outcomes were not correlated $(p>0.05)$. There were fewer cases of depression among the 51 completers compared with all patients following pulmonary rehabilitation (Chi-squared test; $\mathrm{p}<0.0001$ ).
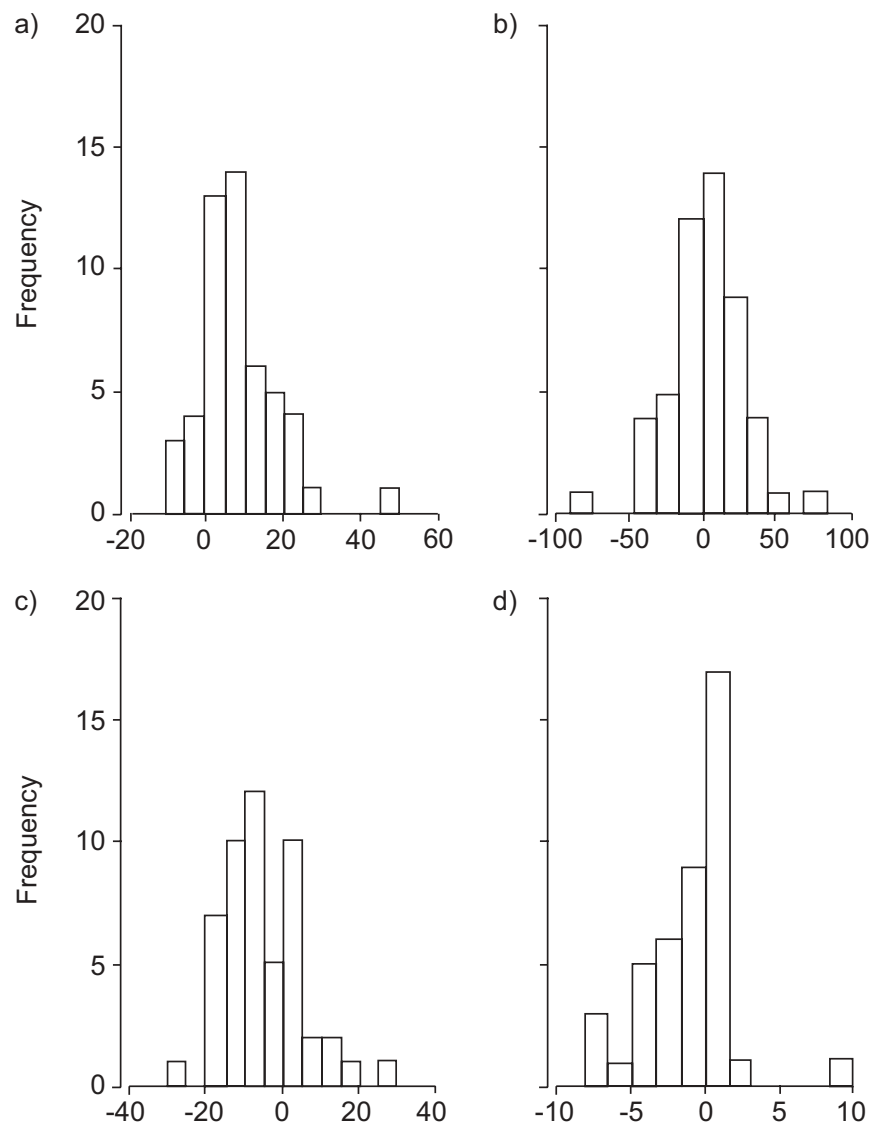

FIGURE 1. Changes in primary outcomes of the following: a) 6-minute walking distance, b) quadriceps strength, c) St George's Respiratory Questionnaire total and d) depression

TABLE 2 Changes in health following pulmonary rehabilitation for patients with mild, moderate or severe disease

Subjects $n$

Disease severity

\begin{tabular}{ccc}
\hline Mild & Moderate & Severe \\
$($ MRC grade 1/2) & (MRC grade 2/3) & (MRC grade 5)
\end{tabular}

6MWD \% pred of normative values 6MWD m

Quadriceps torque Nms

SGRQ score ${ }^{\#}$

MIP \% pred

MEP \% pred

Grip \% pred

COPDSE

LCADL $^{\#}$

$$
\begin{gathered}
7.8 \pm 6.5 \\
54.7 \pm 45.0 \\
1.6 \pm 19.6 \\
-7.5 \pm 10.3 \\
11.1 \pm 22.9 \\
-0.0 \pm 22.7 \\
-0.9 \pm 11.4 \\
0.4 \pm 0.5 \\
-0.4 \pm 3.9
\end{gathered}
$$

$10.0 \pm 11.3$
$68.0 \pm 74.2$
$3.1 \pm 33.8$
$-7.0 \pm 8.4$
$2.7 \pm 10.3$
$10.1 \pm 17.9$
$3.1 \pm 12.3$
$0.1 \pm 0.9$
$-1.1 \pm 7.5$

$5.2 \pm 11.9$

$32.6 \pm 74.8$

$6.5 \pm 18.7$

$0.7 \pm 11.2$

$1.9 \pm 10.5$

$11.3 \pm 31.5$

$-0.6 \pm 19.8$

$0.1 \pm 0.7$

$0.7 \pm 8.5$ p-value

Data are presented as mean difference \pm SD between follow-up and baseline. A positive score=improvement, unless otherwise indicated ( ${ }^{\text {: }}$ negative score=improvement). $\mathrm{p}$-values represent the significance of disease severity in a generalised linear model with score at follow-up as the dependent variable, disease severity as the independent variable and baseline score as a covariate (nonsignificant (NS)=p>0.05). MRC: Medical Research Council; 6MWD: 6-minute walk distance; $\mathrm{SGRQ}=$ St George's Respiratory Questionnaire; MIP: maximal inspiratory pressure; MEP: maximal expiratory pressure; COPDSE: Chronic Obstructive Pulmonary Disease Self-Efficacy Scale; LCADL: London Chest Activity of Daily Living Scale. 


\section{Change in outcomes stratified according to MRC dyspnoea score grade}

Changes in scores for all outcomes for patients with mild, moderate or severe breathlessness are shown in table 2 . Significant differences were seen between the groups for change in $6 \mathrm{MWD}$ and SGRQ Score after controlling for baseline values (ANCOVA main effect $p<0.0001$, effect of severity of breathlessness on 6MWD $\mathrm{p}=0.003$, on SGRQ $\mathrm{p}=0.03$ ). Post hoc analyses showed that only the mild (MRC Grade $1 \& 2$ ) and moderate (MRC Grade 3 \& 4) patients improved in these outcomes.

\section{Predictors of change in outcome measures}

Correlations between the baseline variables and changes in the continuous primary outcomes were tested using Pearson's correlation coefficient (table 3). Those variables showing a significant relationship $(p<0.05)$ were entered into a multiple regression with change in the outcome variable as the dependent variable.

For changes in 6MWD \% pred, lower quadriceps torque (\% body weight) and lower self-efficacy was associated with greater improvement $(p=0.006$ and 0.02 , respectively; adjusted $\mathrm{r}^{2}=0.2$. These variables were not correlated at baseline $(p>0.05)$. For changes in quadriceps strength, patients with lower FEV1 showed greater improvement (adjusted $r^{2}=0.14$; $\mathrm{p}=0.004)$. For changes in SGRQ score, a higher baseline 6MWD $\%$ pred was associated with greater improvement (adjusted $\mathrm{r}^{2}=0.13 ; \mathrm{p}=0.03$ ).

\section{Responders versus nonresponders}

Clinically significant improvement was seen in 24 patients according to the $6 \mathrm{MWD}$, and in 32 patients according to the SGRQ. Clinical improvement in 6MWD was not associated with clinical improvement in health status (Chi-squared test; $\mathrm{p}>0.05)$. According to the current author's prospectively determined composite measure of response, $39(77 \%)$ patients were found to show clinically significant improvement (table 4 shows responders stratified according to MRC dyspnoea score grade). None of the baseline variables were predictors of this response (logistic regression; $\mathrm{p}>0.05$ ).

\begin{tabular}{|c|c|c|c|}
\hline \multirow[t]{2}{*}{ TABLE 3} & \multirow[b]{2}{*}{$\triangle 6 \mathrm{MWD} \%$} & \multirow[b]{2}{*}{$\Delta$ Quads } & \multirow[b]{2}{*}{$\Delta$ SGRQ } \\
\hline & & & \\
\hline Age yrs & -0.1 & -0.0 & 0.2 \\
\hline BMI $\mathbf{k g} \cdot \mathrm{m}^{-2}$ & 0.2 & -0.2 & -0.1 \\
\hline Smoking pack-yrs & -0.1 & 0.1 & 0.0 \\
\hline 6MWD \% pred & $-0.3^{\#}$ & -0.1 & $-0.4^{\circ}$ \\
\hline $\begin{array}{l}\text { Quadriceps maximum } \\
\text { torque Nms }\end{array}$ & -0.2 & -0.1 & -0.2 \\
\hline $\begin{array}{l}\text { Quadriceps } \\
\mathrm{Nms}^{\mathrm{kgg}} \mathrm{g}^{-1} \times 100\end{array}$ & $-0.4^{\circ}$ & -0.1 & -0.1 \\
\hline SGRQ total & 0.2 & -0.1 & -0.0 \\
\hline FEV $1 \%$ pred & -0.0 & $-0.4^{\bullet}$ & -0.1 \\
\hline FVC \% pred & -0.1 & -0.3 & 0.0 \\
\hline MIP \% pred & 0.1 & -0.2 & -0.2 \\
\hline MEP \% pred & -0.1 & -0.2 & -0.1 \\
\hline$V^{\prime} O_{2}, \max \mathbf{k g} \cdot \mathrm{L}^{-1} \cdot \mathrm{min}^{-1}$ & -0.1 & 0.0 & -0.2 \\
\hline MVV & -0.0 & -0.3 & -0.2 \\
\hline MVV/V'E & -0.2 & 0.2 & -0.1 \\
\hline Grip \% pred & 0.0 & -0.0 & 0.0 \\
\hline Borg score pre-6MWD m & 0.2 & 0.1 & 0.1 \\
\hline Borg score post-6MWD m & -0.2 & 0.1 & 0.2 \\
\hline $\mathrm{Sa}, \mathrm{O}_{2}$ pre-6MWD \% & $-0.4^{\bullet}$ & -0.3 & -0.2 \\
\hline $\mathrm{Sa}, \mathrm{O}_{2}$ post-6MWD \% & 0.1 & $-0.4^{\star}$ & -0.2 \\
\hline Heart rate pre-6MWD & $-0.4^{*}$ & -0.1 & 0.1 \\
\hline Heart rate post-6MWD & -0.3 & 0.1 & 0.0 \\
\hline COPDSE & $-0.3^{\#}$ & 0.1 & -0.0 \\
\hline LCADL & 0.2 & 0.0 & 0.2 \\
\hline
\end{tabular}

6MWD: 6-minute walking distance; SGRQ: St George's Respiratory Questionnaire; BMI: body mass index; FEV1: forced expiratory volume in one second; \% pred: per cent predicted; FVC: forced vital capacity; MIP: maximal inspiratory pressure; MEP: maximal expiratory pressure; $V^{\prime} \mathrm{O}_{2}$,max: maximum oxygen consumption; MVV/V'E: maximal voluntary ventilation/ventilation ratio; $\mathrm{Sa}_{1} \mathrm{O}_{2}$ : arterial oxygen saturation; COPDSE: Chronic Obstructive Pulmonary Disease Self-Efficacy Scale; LCADL: London Chest Activity of Daily Living Scale. Borg pre-6MWD values were log transformed in order to achieve a normal distribution prior to analysis. ${ }^{\#}: p<0.05 ; ~ \bullet: p \leqslant 0.01$.

TABLE 4 Percentage of patients completing pulmonary rehabilitation with a clinically significant change in St George's Respiratory Questionnaire (SGRQ) score (reduction of $\geqslant 4$ units) and 6-minute walking distance (6MWD; increase of $\geqslant 54 \mathrm{~m}$ ) stratified by the Medical Research Council dyspnoea score (MRC) grade.

Total

Disease severity

\begin{tabular}{lcccc} 
& Total & \multicolumn{3}{c}{ Disease severity } \\
\cline { 3 - 5 } & & Mild (MRC grade 1/2) & Moderate (MRC grade 2/3) & Severe (MRC grade 5) \\
\hline Subjects $\mathbf{n}$ & 51 & 16 & 22 & 13 \\
$\mathbf{6 M W D} \geqslant \mathbf{5 4} \mathbf{m}$ & 47 & 81 & 59 & 46 \\
$\mathbf{S G R Q}$ score ${ }^{\#} \geqslant \mathbf{4}$ units & 63 & 50 & 50 & 39 \\
Composite responders & 77 & 88 & 82 & 54 \\
\hline
\end{tabular}

Data are presented as $\%$ or $n$. There was no difference between the groups in the number of patients who had changed significantly ( $p>0.05)$. Composite: percentage of patients completing pulmonary rehabilitation with a clinically significant change in either SGRQ score (a reduction of $\geqslant 4$ units) or 6MWD (an increase of $\geqslant 54 \mathrm{~m}$ ) stratified by MRC grade. 


\section{Drop-outs versus completers}

A total of 23 out of the 74 patients (31\%) dropped out of the present study. Of these, five $(24 \%)$ were grade $1 / 2$, seven $(24 \%)$ grade $3 / 4$ and $11(46 \%)$ grade 5 (Chi-squared; $p>0.05)$. The reasons for drop-out were: 1) nonmedical [7]; 2) respiratory illness [10]; and 3) nonrespiratory illness [6]. Severity of breathlessness was not associated with drop-out (ANOVA; $\mathrm{p}>0.05)$. Four variables were found independently to discriminate between drop-outs and completers: quadriceps strength (max torque; $p=0.03)$, smoking pack-yrs $(p=0.04)$, SGRQ score $(p=0.02)$ and depression $(p<0.0001)$. These variables were not highly correlated $(r \leqslant 0.4)$. The combined ability of these variables to predict drop-out was tested using logistic regression. The forward stepwise entry method based on the Wald statistic was used. A model containing quadriceps strength, smoking pack-yrs and depression was found to discriminate between drop-outs and completers (Nagelkerke's $r^{2}=0.45$ ). Depressed patients were found to be considerably more at risk of drop-out than nondepressed patients (odds ratio 8.7; confidence interval 2.8-27.1).

\section{DISCUSSION}

In the present study, 74 COPD patients with a wide range of disease severity were provided with a programme of pulmonary rehabilitation. Approximately equal numbers of patients had mild, moderate or severe breathlessness according to their MRC dyspnoea score grade. This is the first study to demonstrate an improvement in patients with only mild disability (MRC dyspnoea grade 1 or 2). Improvements in exercise tolerance and health status in this group were comparable with grade 3 or 4 patients, those more commonly recruited to pulmonary rehabilitation programmes. This data supports the development of rehabilitation programmes with a view to inclusion of patients whose needs are not commonly recognised in guidelines $[7,8]$.

The current authors used previously defined measures of success for exercise tolerance and health status to identify responders in the present study. A composite end-point of improved exercise tolerance and/or improved health status was used to define success since changes in these two variables after rehabilitation are not strongly correlated, but both are important outcomes. Baseline variables did not predict response using the composite measure or any individual measures of outcome. Change in exercise tolerance was associated with baseline weakness, as found by TROOSTERS et al. [1], although, unlike those authors, the present authors did not find ventilatory reserve to be a predictor. In part, the present findings may differ from those of TROOSTERS et al. [1] due to differences in analysis. The current authors performed a more conservative regression analysis, using a forward stepwise entry method. This is less likely than the backwards entry method, used by TROOSTERS et al. [1], to capitalise on chance findings [21]. Additionally, the authors included patients with very significant disability in the present study; only one grade 5 patient was able to exercise sufficiently to achieve an anaerobic threshold.

Predictive factors for rehabilitation remain elusive and selection criteria are difficult to refine. Regression to the mean effects exacerbates the difficulty in performing these studies. Studies using baseline walking distance as a predictor of improvement in exercise tolerance are likely to demonstrate regression to the mean effects due to relationships between baseline variables. This may account for the finding of CILIONE et al. [5] who showed that lower initial walking distance was predictive of a greater change in walking distance after rehabilitation. The current author's post hoc analysis compared overall change and showed a smaller magnitude of improvement in grade 5 patients and a significant effect of initial breathlessness on change in exercise tolerance. This finding is in accordance with previous work, which showed a smaller magnitude of improvement in Grade 5 patients [6]. However, in the study by WEDZICHA et al. [6], the rehabilitation programmes differed between groups [22]. In the current study, all patients received an identical training programme, and exercise prescription was based on the results of an initial incremental walking test. However, some of the severely breathless patients were responders; of the grade 6 patients who completed the 7 -week course, five (46\%) achieved a clinically significant improvement in exercise tolerance. MRC dyspnoea score grade, whilst useful [23, 24], should not be used as primary grounds for exclusion. Patient preference and clinical judgement remains the cornerstone of appropriate selection.

A significant problem in the evaluation of rehabilitation remains that true intention-to-treat analysis is effectively impossible to achieve. Almost twice as many of the presented grade 5 patients who entered into the study were unable to complete the programme compared with the other groups. This was despite the provision of transport, regular encouragement and alternative sessions for missed attendance.

In the current study, the authors examined the link between depression, muscle weakness and drop-out. In conclusion, the role played by depression in undermining benefits of pulmonary rehabilitation, whilst previously recognised [25], may have been underestimated. In the present study, patients with lower quadriceps strength, higher smoking pack-yrs and who were depressed were more likely to drop out. In fact, depressed patients were almost twice as likely to drop out compared with those who were not depressed. The present authors recommend that further research is performed in this area.

\section{ACKNOWLEDGEMENTS}

The authors would like to acknowledge the generous support of the Health Foundation in funding this study and the help of J. Dogherty. The authors would also like to thank V. Pomeroy (Centre for Rehabilitation and Ageing, St George's Hospital, University of London, London, UK) for her helpful contribution.

\section{REFERENCES}

1 Troosters T, Gosselink R, Decramer M. Exercise training in COPD: how to distinguish responders from nonresponders. J Cardiopulm Rehabil 2001; 21: 10-17.

2 Garrod R, Ford K, Daly C, Hoareau C, Howard M, Simmonds C. Pulmonary rehabilitation: analysis of a clinical service. Physiother Res Int 2004; 9: 111-120.

3 Niederman MS, Clemente PH, Fein AM, et al. Benefits of a multidisciplinary pulmonary rehabilitation program. 
Improvements are independent of lung function. Chest 1991; 99: 798-804.

4 Vogiatzis I, Williamson AF, Miles J, Taylor IK. Physiological response to moderate exercise workloads in a pulmonary rehabilitation program in patients with varying degrees of airflow obstruction. Chest 1999; 116: 1200-1207.

5 Cilione C, L.orenzi C, Dell OD, et al. Predictors of change in exercise capacity after comprehensive COPD inpatient rehabilitation. Med Sci Monit 2002; 8: CR740-CR745.

6 Wedzicha JA, Bestall JC, Garrod R, Garnham R, Paul EA, Jones PW. Randomized controlled trial of pulmonary rehabilitation in severe chronic obstructive pulmonary disease patients, stratified with the MRC dyspnoea scale. Eur Respir J 1998; 12: 363-369.

7 British Thoracic Society. Pulmonary rehabilitation. Thorax 2001; 56: 827-834.

8 National Institute for Clinical Effectiveness. The National Collaborating Centre for Chronic Disease. Thorax 2004; 59: Suppl. 1, 1-232.

9 British Thoracic Society. BTS guidelines for the management of chronic obstructive pulmonary disease. The COPD Guidelines Group of the Standards of Care Committee of the BTS. Thorax 1997; 52: Suppl. 5, S1-28.

10 Burdon JG, Juniper EF, Killian KJ, Hargreave FE, Campbell EJ. The perception of breathlessness in asthma. Am Rev Respir Dis 1982; 126: 825-828.

11 ATS statement: guidelines for the six-minute walk test. $A m$ J Respir Crit Care Med 2002; 166: 111-117.

12 Enright PL, Sherrill DL. Reference equations for the sixminute walk in healthy adults. Am J Respir Crit Care Med 1998; 158: Suppl. 5, 1384-1387.

13 Jones PW, Quirk FH, Baveystock CM, Littlejohns P. A selfcomplete measure of health status for chronic airflow limitation. The St. George's Respiratory Questionnaire. Am Rev Respir Dis 1992; 145: 1321-1327.

14 Yohannes AM, Baldwin RC, Connolly MJ. Depression and anxiety in elderly outpatients with chronic obstructive pulmonary disease: prevalence, and validation of the BASDEC screening questionnaire. Int J Geriatr Psychiatry 2000; 15: 1090-1096.

15 Garrod R, Bestall JC, Paul EA, Wedzicha JA, Jones PW. Development and validation of a standardized measure of activity of daily living in patients with severe COPD: the London Chest Activity of Daily Living scale (LCADL). Respir Med 2000; 94: 589-596.

16 Garrod R, Paul EA, Wedzicha JA. An evaluation of the reliability and sensitivity of the London Chest activity of Daily Living Scale (LCADL). Respir Med 2002; 96: 725-730.

17 Wigal JK, Creer TL, Kotses H. The COPD Self-Efficacy Scale. Chest 1991; 99: 1193-1196.

18 Naughton J, Sevelius G, Balke B. Physiological responses of normal and pathological subjects to a modified work capacity test. J Sports Med Phys Fitness 1963; 44: 201-207.

19 Redelmeier DA, Bayoumi AM, Goldstein RS, Guyatt GH. Interpreting small differences in functional status: the six minute walk test in chronic lung disease patients. Am J Respir Crit Care Med 1997; 155: 1278-1282.

20 Jones PW. Health status measurement in chronic obstructive pulmonary disease. Thorax 2001; 56: 880-887.

21 Howell DC. Statistical Methods for Psychology. 3rd Edn. Boston, MA, USA, PWS-Kent Publishing Company, 1992.

22 Morgan MD. The prediction of benefit from pulmonary rehabilitation: setting, training intensity and the effect of selection by disability. Thorax 1999; 54: Suppl. 2, S3-S7.

23 Bestall JC, Paul EA, Garrod R, Garnham R, Jones PW, Wedzicha JA. Usefulness of the Medical Research Council (MRC) dyspnoea scale as a measure of disability in patients with chronic obstructive pulmonary disease. Thorax 1999; 54: 581-586.

24 Nishimura K, Izumi T, Tsukino M, Oga T. Dyspnea is a better predictor of 5-year survival than airway obstruction in patients with COPD. Chest 2002; 121: 1434-1440.

25 Young P, Dewse M, Fergusson W, Kolbe J. Respiratory rehabilitation in chronic obstructive pulmonary disease: predictors of nonadherence. Eur Respir J 1999; 13: 855-859. 